УАK 327

ББК 66.4(0)

DOI 10.22394/1682-2358-2018-6-13-21

A.A. Korobov, Doctor of Sciences (Politics), Professor of the Political Sciences Department, Povolzbsky Institute of Management named after P.A. Stolypin, Branch of the Russian Presidential Academy of National Economy and Public Administration

T.N. Okilov, post-graduate student of Tajik State University of Law, Business and Polics, Kbujand

\section{TRANSNATIONAL CORPORATIONS AS SUBJECTS OF CONTEMPORARY INTERNATIONAL CONFLICTS AND CRISES}

The political and geopolitical essence of modern transnational corporations is revealed in the context of the crisis development of the system of international relations. The destructive nature of the political activities of TNCs in relation to both individual states and interstate interactions are considered. Hidden contradictions between modern states and TNCs are revealed, the idea of the increasing opposition between these subjects in the foreseeable future is substantiated.

Key words and word-combinations: international and domestic political conflicts, political crisis, international tension, transnational corporation.
A.A. Коробов, доктор политических наук, профессор кафедрь политических наук Поволжского института управления имени П.А. Стольпина - филиала Российской академии народного хозяйства и государственной служби при Президенте РФ (email:aakorobov@inbox.ru)

T.H. Окилов, аспирант таджикского государственного университета права, бизнеса и политики, Худжанд (email: bobojon1976@yandex.ru)

\section{ТРАНСНАЦИОНААЬНЫЕ КОРПОРАЦИИ \\ КАК СУБЪЕКТЫ \\ СОВРЕМЕННЫХ МЕЖАУНАРОАНЫХ КОНФАИКТОВ И КРИЗИСОВ}

Аннотация. Раскрывается политическая и геополитическая сущность современных транснациональных корпораций в контексте кризисного развития системы международных отношений. Рассматривается деструктивный характер политической деятельности ТНК по отношению как к отдельным государствам, так и межгосударственным взаимодействиям. Выявляются скрытые противоречия между современными государствами и ТНК, обосновывается мысль о возрастании противостояния этих субъектов в обозримом будущем.

Ключевые слова и словосочетания: международные и внутриполитические конфликты, политический кризис, международная напряженность, транснациональная корпорация.

B второй половине ХХ в. транснационамьные корпорации (ТНК) постепенно 
заняли устойчивое положение среАи основных субъектов мировой политики: суверенных государств, союзов государств, международных организаций и т.п. В Аанный исторический период у ТНК четко оформились собственные политические интересы, обусловленные постоянно возрастающими потребностями в дешевом сырье и ресурсах, в оптимальных условиях, географическом положении, режиме производств и цогистике, в новых рынках сбы-

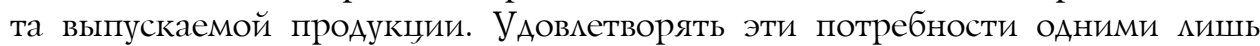
экономическими методами становилось все более трудно, а порой даже невозможно (нерентабельно и невыгодно), вследствие чего ТНК стали Аополнительно использовать политико-дипломатические среАства Аця повышения эффективности решения своих корпоративных задач. Со временем у каждой крупной корпорации сформировался собственный политический вектор Аеятельности.

В сферу политических интересов современных транснациональных корпораций попадают государства и целые группы государств, на территориях которых располагаются сырьевые базы, производства, транспортные узлы и рынки сбыта, необходимые Аля нормального функционирования и развития корпораций. ТНК проявляют естественное стремление к максимацьно возможному контролю наА соџиально-политическими и экономическими процессами, протекающими в этих странах. Отсюда возникают три весьма существенных в теоретико-прикцаАном аспекте проблемы, обусловливающие актуацьность и повышенный научный интерес к вопросу конфмиктогенности ТНК в современной межАународной политике: а) вмешательство во внутренние Аела государства иностранным актором (проблема нарушения государственного суверенитета); б) политический моббизм, осуществцяемый часто вне правового поля; в) искусственное создание очагов напряженности, конфронтации в интересах ТНК.

Конфликтогенность современных ТНК может быть оценена в определенном приближении как имманентная (внутренне присущая) характеристика их деятельности. Такая оценка явцяется производной, во-первых, от нацичия жесткой конкуренџии в глобальном экономическом пространстве и, во-вторых, от стремления каждой корпорации к получению сверхприбыли - цели, достижение которой, как считают многие, оправдывает мюбые средства. Но во всяком конфликте, который интерпретируется в мировой науке как крайняя форма обострения противоречий или столкновение сиц, интересов субъектов, всегда присутствуют как минимум две стороны, а чаще - более Авух; и если одной стороной является транснаџиональная корпорация, то в качестве Аругой (враждебной) стороны могут выступать конкурирующие ТНК и крупные монополистические национацьные компании, официальные органы власти в государстве, политическая парламентская и непарламентская оппозиция, отдельные профильные министерства и ведомства, вкАючая дипмоматическое и военное, международные или национацьные экологические организации и даже отдельные народы, компактно проживающие на той или иной территории. Следовательно, ТНК может явцяться прямым или косвенным участником, субъектом как межАународного, так и внутригосударствен-

14 Bulletin of the Volga Region Institute of Administration • 2018. Vol. 18. № 6 
ного конфликта, как политического, так и военного, экономического (торгового, финансового), экологического конфликта.

Отметим, что интеграционные проџессы в мире развиваются весьма быстрыми темпами. Мир меняется, увеличивается насемение планеты, природные ресурсы истощаются, и на этом фоне наиболее ярко наблюдается увеличивающаяся конкуренџия между ТНК. Корпорациям становится все сложнее конкурировать между собой, и они начинают искать поддержку отдельных суверенных государств, вступают в переговоры с представителями национальных элит. Аля более быстрого получения доступа к рынку или ресурсной базе этих стран ТНК иногда прибегают к Аавлению, подкупу, шантажу представителей власти; если это не дает результата, то корпорации могут прибегнуть и к созданию в стране внутриполитической конфликтной ситуации, чтобы привести к власти мояльных в отношении них политиков. «Государства все более утрачивают национальный контроль над развитием ТНК, которые пока что «соглашаются» подчиниться сушествуюшему порядку (праву), в то время как эффективного межАународного контроля их деятельности еще не создано» $[1$, с. 42$]$.

В данном контексте немаловажным явмяется вопрос: что собой представмяют современные транснациональные корпорации? Согласно исследованиям, проведенным Швейцарским федеральным технологическим институтом в Цюрихе (Swiss Federal Institute of Technology), основу всех ТНК составляют финансовые группы, которые имеют большое влияние на глобальную мировую экономику, равно как и на международную политику. По мнению Ика Ниа Мба, современные «ТНК становятся более кросс-культурными, то есть в ТНК могут работать мюди разных наџиональностей, где вопрос о наџиональной принадлежности или идентичности будет стоять на втором плане» [2, с. 86-94]. ТНК заинтересованы в привлечении мюдей из разных регионов и стран, чтобы унифицировать всех не по национальным признакам, а с точки зрения получения доступа к разным рынкам.

ТНК имеют представительства, региональные офисы, дочерние компании во многих странах, управляемые головным офисом или несколькими офисами из разных точек мира. По данным Инвестопедии (Investopedia) 2014 г., почти все современные крупные ТНК явмяются мибо американскими, мибо японскими [3]. Представляется возможным условно разделить ТНК на два больших класса: ТНК с азиатским уклоном и ТНК с европейским уклоном ведения деятельности. Как показывает анализ деятельности современных транснациональных корпораций, ТНК с азиатским уклоном ведения деятельности осуществляют более мягкую наступательную интервенционную политику по отношению к государствам, а второй класс корпораций, напротив, ведет более жесткую, бескомпромиссную борьбу за реализаџию своих политических интересов. Аюбая же интервенция, борьба - это уже столкновение сил, конфликт. Получается, что ТНК непрерывно ведут борьбу (чаще мягкую, чем жесткую бескомпромиссную) за получение доступа к ресурсам, транспортным коммуникациям, инфраструктуре и рынкам интересующих их государств, в чем и проявляется конфмиктогенность ТНК. 
Основной целью транснациональных корпораций явмяется получение прибыли (в идеале - сверхприбыли), а не занятия политикой; но в то же время им нужны механизмы контроля, влияния или формирования политики, что, собственно, и делает их субъектами международной политики. Манипукируя властью в отдельном государстве, корпорации могут продвигать и реализовывать собственные политические и экономические интересы. ОАнако, по мнению ряда исследователей, модель мировой политики и экономики с Аоминирующей ролью ТНК содержит в себе большой риск, состоящий в возникновении различных кризисов, в первую очередь - финансовых. Так как в мире все взаимосвязано, при появлении проблемы в одной из этих мега-организаций возникает «эффект домино»: проблемой поочередно «заражаются» остальные хозяйствующие в мировом экономическом пространстве субъекты, и в итоге страдает вся мировая экономика. Примером может служить финансовый кризис 2008 г., когда компания «Lehman Brothers» неожиданно и резко оказалась в нестабильном состоянии, и это повлияло на возникновение глобального финансового кризиса.

Соглашаясь в целом с приведенным мнением тем не менее внесем некоторую корректировку. Ранее причины экономических кризисов цежали в области перепроизводства товаров, услуг, то есть материальных благ. Кризисы носили объективный, во многом циклический характер, обусловленный самой природой капитализма. От них обычно страдал и малый, и средний, и крупный бизнес, не говоря о простом населении. ОАнако постепенно обществом были выработаны эффективные меры борьбы с такими кризисами и их социальными последствиями, в результате чего кризисы, особенно мокальные, стали во многом управмяемыми, а значит проектируемыми, планируемыми. Это кАючевой момент - современные политические, финансовые и экономические кризисы в отдельно взятом государстве или в целом ряде государств могут быть искусственно созданы транснациональной корпорацией или трастом с целью передела собственности, перекраивания рынка в свою пользу. Во время кризиса (не только финансового, но и политического), а также во время гражданских войн, происходят, во-первых, обвал акций различных компаний на фондовых площадках - их тут же скупают по очень низкой цене представители ТНК; во-вторых, массовые банкротства фирм - их новыми владельцами становятся представители международных корпораџий или же происходит классическая расчистка сектора Аля создания полной монополии. Все это свидетельствует о прямой заинтересованности крупных транснациональных корпораџий в создании кризисов в странах, находящихся в сфере их политических интересов.

По мере возникновения и развития политического кризиса всегда кто-то оказывается в выигрыше, а кто-то - в проигрыше. Тем ТНК, которые нахоАятся в выигрыше, кризис приносит прибыль, а те, которые оказались в проигрыше и понесли убытки, стремятся «отыграться» и компенсировать свои потери. А^я компенсаџии потерь транснациональные корпораџии начинают искать выход, то есть выбирают новые страны, где можно быстро получить АохоА. Если в этой стране политическая обстановка стабильна, а с властью 
сложно, Аолго ици невыгодно Аоговариваться, тогда имеет смысл создать там хаос, причем он Аолжен быть непременно управцяемым. Управцяемый хаос - это политическая теория и практика, которые используются в большинстве случаев Соединенными Штатами Америки с целью погружения Аругих стран в хаос путем организации гражданских войн, межнациональной напряженности, экономических, продовольственных проблем, коррупџии и т.А. Аанный механизм обычно разрабатывается и внеАряется при помощи спецслужб, через Аипломатический корпус за рубежом и вооруженные силы. Путем создания управляемого хаоса США могут сохранять определенный контроль наА интересующей их страной и получать необхоАимую выгоду через ТНК, выкачивая человеческие, финансовые и сырьевые ресурсы, что позволяет США поднимать уровень жкизни в своей стране за счет снижения в Аругих.

Возможны два варианта деструктивной политической деятельности ТНК: если корпорация располагает собственными ресурсами Аля организации в стране политического хаоса, она выступает непосредственным зачинщиком или провокатором дестабилизации политической обстановки; если же корпорация такими ресурсами не обладает, она может подтолкнуть к агрессии

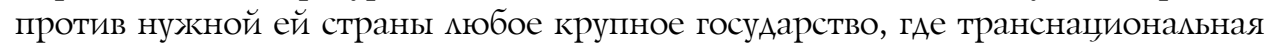
корпорация имеет свое политическое мобби, например, США. На практике чаще всего реализуется второй вариант, что дает основания экспертам-международникам утверждать, что практически все страны Запада проводят свою агрессивную внешнюю политику в интересах узкого круга финансовых групп и подконтрольных им транснаџиональных корпораций. Но нередко набцюАается и первый вариант самостоятельной реализации ТНК своих политических интересов, особенно в отношении экономически отсталых стран Африки, Карибского бассейна и т.п.

Рассмотрим непосредственные приемы создания транснациональными корпорациями управцяемого политического хаоса. В создании мюбого управляемого хаоса, равно как и мокацьных, внутриполитических конфмиктов, большую роль играют средства массовой информации. СМИ часто называют четвертой ветвью власти. В СМИ западных стран, в том числе в США, распространение можных сведений или фейковых новостей считается нормальным явлением. Распространение можной информации делается в первую очередь Аля формирования общественного мнения вокруг той ици иной страны или проблемы; а далее все решается по заранее придуманному плану. Примером этому могут быть ракетные удары по сирийским городам якобы из-за применения в САР химического оружия президентскими войсками Башара Асада в 2017 и 2018 гг.

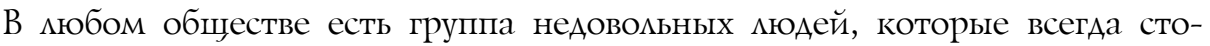
ят в оппозиџии к мюбой вмасти. Их условно можно назвать потенциальными провокаторами, или деструктивными силами, в обществе. Согласно идее Э. Фромма, высказанной им в книге «Анатомия человеческой деструктивности», деструктивность изначально заложена в человеке; следовательно, в бом обществе ужке существуют (пусть дажке в небольшом количестве) нужкные 
Аля организации хаоса деструктивные индивидуумы, которые Аля Аостижения поставленной цели будут получать финансовую подпитку от ТНК через, например, неправительственные организации, фонды, имеющие официальную регистрацию в стране их проживания [4] . Такая группа мюдей обычно муссирует распространяемую через СМИ Аюбую фейковую новость. Аанная схема особенно хорошо работает в процессе политических выборов, от которых зависит получение доступа ТНК к рынкам сбыта.

Провоцируя массу мюдей, можно организовать государственный переворот или войну, ярким примером тому служит Украина, где бым широко задействован механизм разнообразных политтехнологий. Используя Аанный механизм, мегко сменить мюбого мидера, и через подАержку фиктивных выборов поставить на его место того, кто будет служить преимущественно интересам ТНК, а не интересам избравшего его народа. Предоставление политических консультаций или советов, использование различных избирательных технологий и PR-технологий, моббирования входит в арсенал современных политических технологий, который широко используется в качестве средств организации войны и государственных переворотов на мировом уровне. Государству преАоставцяются политические консультаџии и советы во время предвыборной кампании или принятия судьбоносных Аля страны решений с привлечением крупных аналитических центров, что, в свою очереАь, опреАеляет степень влияния местной политической элиты на политический проџесс в государстве. Таким образом, используя метод моббирования интересов тех или иных групп в обществе, ТНК могут Аостичь цели в получении необходимого результата, при этом широко используются СМИ и Аругие среАства связи Аля «промывки мозгов» и Аостижения цели.

Отметим, что конфликтогенность транснационацьных корпораций проявляется в нескольких плоскостях. Во-первых, ТНК целенаправленно развязывает в отдельном регионе мира межгосударственный конфликт (чаще Авусторонний, но бывает и многосторонний), и в ходе конфликта, особенно находящегося в военной фазе, «оказывает помощь» одновременно всем враждующим сторонам. Так было, например, в ходе ирано-иракской войны. Американские корпорации поставцяли Ираку технологии двойного назначения, оружие, произведенное не в США; быма также оказана экономическая помощь в размере мимлиарда домларов. Парамлекьно с этим в Иран были организованы поставки амуниџии по защите от химического оружия, причем сначала в Иран поставцяли амуниџию по защите от химического нападения, а позже бымо организовано нападение, в ходе которого более 200 тысяч иранцев быми убиты или искамечены навсегда [5]. Во-вторых, ТНК цеменаправленно развязывает в отдельном государстве конфликт правящей элиты с оппозицией, часто подАержииает сепаратистов и радикально настроенные силы. Цель организации внутригосударственного конфмикта дия ТНК, начиная от «цветных» револющий и заканчивая гражданскими войнами, - управмение странами и внедрение в них своих правиц ведения бизнеса. Большинство таких конфликтов в мире происходит в тех регионах, где ТНК имеют больше интересов или где имеется пересечение интересов ТНК. К Аанным 
регионам прежде всего можно отнести богатые нефтегазовыми ресурсами, то есть регион Ближнего Востока, и редкоземельными полезными ископаемыми - центральную часть Африканского континента. В-третьих, ТНК провоцирует политический кризис, чтобы произвести передел рынка. В-четвертых, транснациональные корпорации из военно-промышиенного сектора мировой экономики заинтересованы в непрерывных войнах и военных конфликтах по всему миру, которые обусловливают непрерывный спрос на производимую этими корпорациями продукцию (военную технику, оружие, обмундирование и т.п.).

На примере Аемократической Республики Конго отчетливо видна реальная роль транснациональных корпораций в дестабилизаџии соџиально-политической обстановки в стране: создание и поддержание политической нестабильности, политического хаоса (безвластия), непрерывных вооруженных столкновений. Обострение политической обстановки в Республике приводит к тяжелым соџиальным, экономическим и экологическим последствиям Аля всего населения страны: возникновению вынужденной миграции населения, потере Аюдьми прежних мест проживания, голоду, истреблению местными жителями месов и диких животных для обеспечения пропитания, болезням, росту государственного Аолга [6] .

Военно-промышленные ТНК имеют еще большую заинтересованность в распространении по миру очагов вооруженных столкновений, но природа их интереса к подобному роду конфциктов несколько иная. Чтобы оборонная промышкенность развивалась, получала непрерывный доход, необходимо

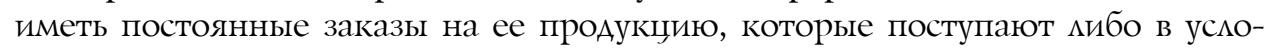

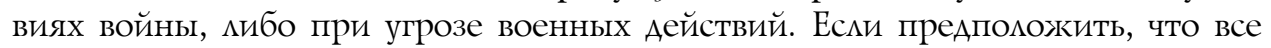
страны начали жить межАу собой в гармонии и взаимопонимании, то пропаАет необходимость обороняться Аруг от Аруга и исчезнет всякий спрос на проАукцию военной (оборонной) промышиенности. Но здесь становится актуаАьным английский внешнеполитический принџип "разделяй и властвуй». Если, например, разделить страны на более мелкие территории по религиозным или иным признакам, ими можно будет мегко манипулировать. Пример Индия и Пакистан, которые на протяжении многих иет не могут найти решения территориального спора по Кашмиру. Эта проблема явцяется источником конфцикта в регионе. Нечто похожее наблюдалось при распаде на суверенные государства Французской Экваториальной Африки, позднее - Соџиалистической Федеративной Республики Югославии, а затем при отсоединении Косова от Сербии. Аюбая война Аля военно-промышиенных ТНК - это не только реальный доход, но еще и отличная реклама новых видов вооружений, отработка (испытания) современных образцов оружия, поэтому, как правицо, при начале крупных региональных вооруженных конфликтов акции транснациональных корпоращий, чье оружие и техника используется в сражениях, резко растут в цене.

Отсюда можно сделать следующее умозаключение: современные военнопромышленные ТНК всегда поддерживают планы ведущих держав (таких государств, как США, Великобритания, Франция) по проведению разнообраз- 
ных военных кампаний, свержению неугодных Западу политических режимов и могут даже выступать в роли подстрекатемей. Такие корпорации заинтересованы в росте напряженности международных отношений между странами Запада и Российской Федерацией, в усилении «холодной войны». Своих целей THК Аобиваются посреАством формирования влиятельных цобби в национальных правительствах веАущих стран мира.

В США многие крупные ТНК прямо или косвенно имеют отношение к оборонной промышиенности. В интересах ее развития государство само (естественно, с подачи моббистов военно-промышиенных ТНК) ищет рынки сбыта производимой ею военной продукщии. ОАним из вариантов нахождения рынков сбыта явцяется искусственное создание организованного конфАикта, или «горячих точек», там, где есть ресурсы Аля приобретения оружия. Примером могут служить страны Ближнего и Среднего Востока, где имеются территориальный конфликт межАу Палестиной и Израилем, религиозный конфликт межАу Саудовской Аравией и Ираном, межклановые войны в Афганистане, сложносоставной вооруженный конфликт в Сирийской Арабской Республике и т.А.

Афганистан занимает особое место в сфере политических интересов транснациональных военно-промышменных корпораций мира [7]. Во-первых, там глубокие межэтнические и межккановые противоречия, обусловмивающие непрекращающиеся вооруженные конфликты на его территории последние сорок мет. Во-вторых, Афганистан - удобный полигон Аля испытания новейших видов вооружения, разрабатываемых корпораџиями, в реальных полевых условиях. В-третьих, Афганистан считается крупным экспортером наркотиков в страны Запада и плаудармом многих террористических организаций.

По этим причинам ТНК могут использовать Исламскую Республику Афганистан одновременно в нескольких качествах: продавать враждующим на ее территории этническим группам и кланам военную технику и оружие; ссыцаясь на террористическую угрозу из Афганистана, ТНК могут весьма эффективно моббировать свои интересы в правительствах стран Запада, помучать от них заказы и приличное финансирование; открыто поддерживая в вооруженных столкновениях так называемые «демократические силы», корпораџия способна созАать позитивный политический имиАж борџа против межАународной террористической угрозы, борџа за свободу, независимость и проџветание всего афганского народа, что мегко осуществияется через подконтрольные корпораџии, местные и мировые СМИ, формирующие общественное мнение.

Аобавим последний штрих к получившейся общей картине конфликтогенности современных ТНК в мировой политике. Как бы ни была та или иная транснаџиональная корпораџия заинтересована в дестабилизаџии политической и соџиально-экономической обстановки в регионе, организовать искусственный конфцикт (ими способствовать его появлению, усицению) можно мишь при наличии ряда условий, главным из которых явмяется существование в обществе мюбых прочных и глубоких противоречий. Организаџия конфмик- 
та состоит из следующих элементов: финансовой поддержки конфликтующих сторон; материальной подлержки участников конфликта (поставки конфликтующим сторонам военных товаров и услуг); консалтинговых услуг (отправки военных советников, помощников и т.п.).

Рассмотрев конфликтогенность современных транснациональных корпораџий в межАународной политике, можно сделать следующие обобщения и ВЫВОАЫ.

Во-первых, если мокамьный экономический / финансовый кризис может быть спровоцирован ТНК с целью передела национального или регионального рынка в интересах корпорации, то внутриполитический кризис частопровоцируется транснаџиональной корпораџий, чтобы поставить поА свой контроль внутреннюю и внешнюю политику государства (не дать ему возможность проводить независимую политику), находящегося в сфере ее политических и экономических интересов.

Во-вторых, участие (прямое или косвенное) в мокальных военных конфмиктах выгодно как транснациональным корпорациям военно-промышленной (оборонной) отрасли, так и ТНК из иных отраслей мировой экономики. В первом случае интенсивность боевых действий приводит к стремительному росту стоимости акџий ТНК - производителей военной техники и оружия, обеспечивая существенный рост капитализаџии корпораџии. Во втором - обмегчает доступ корпорациям к сырью, ограниченной ресурсной базе, инфраструктуре, позволяет занять доминирующее (монопольное) положение на рынке. Следовательно, мюбая война выгодна в первую очередь тем ТНК, которые прямо ици косвенно имеют отношение к организаџии и ведению Аанной войны.

В-третьих, противостояние межАу государствами и ТНК на мировой политической арене в обозримом будущем будет неуклонно возрастать. Это приведет к увеличению степени конфликтогенности транснациональных корпораций и, соответственно, к повышению уровня риска устойчивому развитию мировой политики и системе межАународных отношений.

\section{Библиографический список}

1. Владимиров А.И. «Железная пята ТНК»: глобализация, война и мир третьего тысячелетия // Пространство и время. 2012. № 1 (7).

2. Ika Nia Mba. Journal of International Business and Economics // Published by American Research Institute for Policy Development. 2015. T. 3, № 1.

3. Фромм Э. Анатомия человеческой деструктивности. М., 2015.

4. Multinational Corporation - MNC. URL: https://www.investopedia.com/terms $/ \mathrm{m} / \mathrm{multina}-$ tionalcorporation.asp

5. Белоусова К.А. Ирано-иракская война (1980-1988) и политика CША в Ираке. URL: https://cyberleninka.ru/article/v/irano-irakskaya-voyna-1980-1988-i-politika-ssha-v-irake

6. Окилов T.Н. Конфликтогенность транснациональных компаний в современной международной политике // Вестник Поволжского института управления. 2018. Т. 18, № 4.

7. Поздняков А.И. Глобализация и ее влияние на международную безопасность и военную политику Российской Федерации // Пространство и время. 2011. № 2. 